\title{
Launching IALS Digital: Connections and Collaboration
}

Steven Whittle, IALS Digital Manager, Institute of Advanced Legal Studies, School of Advanced Study, University of London

Abstract: During its $70^{\text {th }}$ Anniversary celebrations the Institute of Advanced Legal Studies, School of Advanced Study, University of London launched IALS Digital - a new name for established and evolving online services at IALS, bringing together resources, opportunities for new legal information initiatives, research projects and partnerships, and delivering support for digital legal scholarship. This paper, developed from presentations at the launch in November 2017, reports on the event and describes what the Institute plans to achieve through IALS Digital - explaining what it is, how it has developed and how it fits well with the IALS national role in the promotion and facilitation of legal research.

Keywords: Digital legal scholarship; digitisation; free legal information; legal research; legal sources; open access; Commonwealth; Institute of Advanced Legal Studies

\section{What is IALS Digital?}

As part of its $70^{\text {th }}$ anniversary celebrations in November 2017 the Institute of Advanced Legal Studies launched IALS Digital, a new name for established and evolving online services at the IALS - bringing together resources; creating opportunities for new legal information initiatives, research projects and partnerships; and providing support for digital legal scholarship.

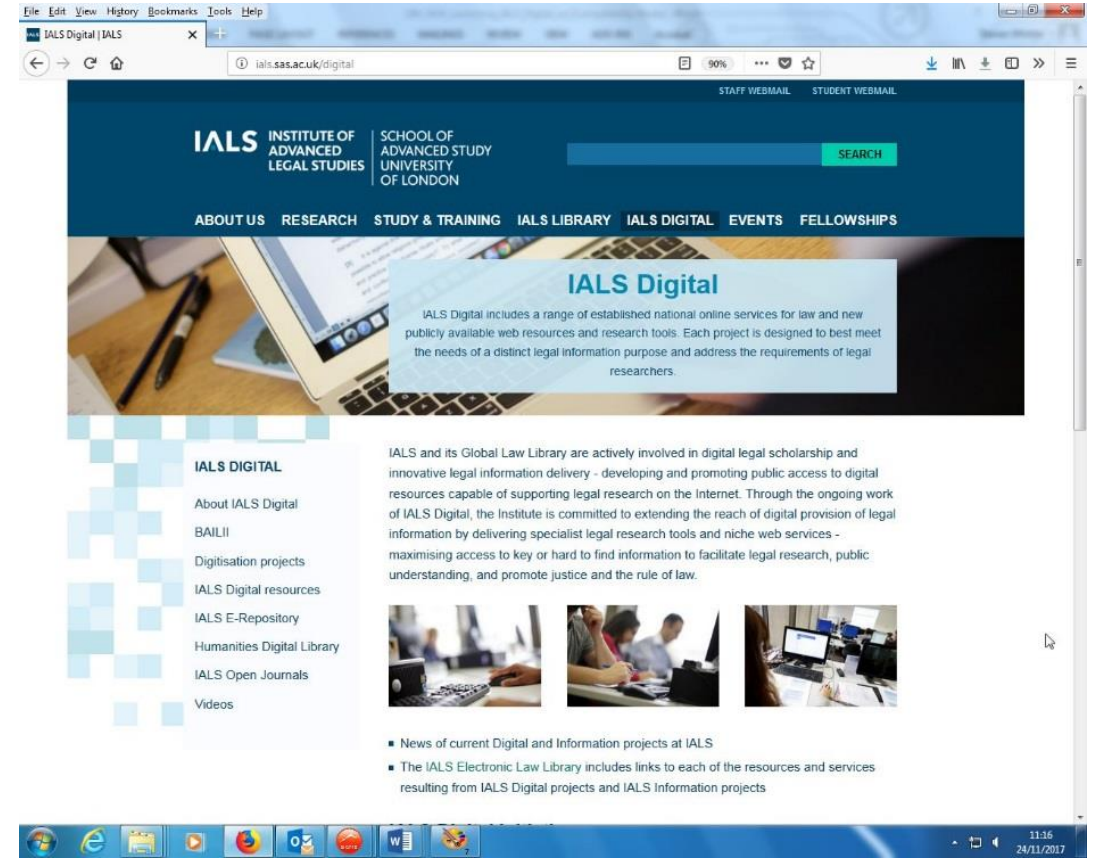

At the Institute, particularly in the Library, we have been actively involved in innovative national legal information delivery for many years, developing and promoting public access to law and legal research materials on the Internet through the creation of a range of award winning web resources, digitisation projects, and collaborative ventures such as the hosting of the British and Irish Legal Information Institute (BAILII). IALS is often consulted by potential partners and others to advise on the digital aspects of projects, on the preservation 
or hosting of websites and is active in the field of open journal publication, open monograph publication and online research training.

Building on this successful experience, IALS Digital has been formed as a multitasking initiative: as a service, as a team, and a set of freely available legal research resources. IALS Digital is all about connections and collaboration - linking people to legal information, linking people to each other, and co-operating with likeminded partners in developing resources and services that are beneficial to legal academics and legal professionals and the wider public interest. We anticipate that it will involve working on new ideas, new forms of work and new ways of working together.

\section{IALS Digital - the service and its team}

Our established services are drawn from information initiatives, unique collections and expertise in creating, sharing and using legal information at the Institute which have been key in creating and delivering freely available legal research resources on the web. Work with these resources will continue, complemented by more work on technology-related research methods. As a developing service we see IALS Digital exploring new technology and investigating its application for legal research. Such work will include providing new content, linking data to add research value and provide wider contexts to the information, and digital skills sharing.

Open law initiatives, enabled by digital communications and curation and their potential for transforming information, are at the heart of the IALS Digital mission, founded in the shared recognition of the fundamental importance to all forms of legal research and the wider public interest of open access to authentic primary materials, such as legislation and case reports, coupled with open access to commentary and scholarly insight. Our ambitions for open law include extending the role of digital publishing of legal scholarship and the development of online research publications.

The IALS Digital team is comprised of law librarians with a background in legal information management and information systems skills. A core team (Lindsey Caffin, Narayana Harave, and Steven Whittle) is working with other sections of the Institute Library, particularly the Academic Services team, and with academic and administrative staff in the Institute and more widely in the School of Advanced Study as well as drawing on help from colleagues in the University of London Computer Centre.

IALS Digital is very much a collaborative enterprise drawing, particularly in its open law projects, on academic and professional legal expertise across the UK and internationally. For example, the speech by Professor Graham Greenleaf AM (Professor of Law \& Information Systems, UNSW; Founding Co-Director \& Senior Researcher, Australasian Legal Information Institute (AustLII)) for the Free the Law event that started BAILII was written at IALS and IALS has continued to work cooperatively with AustLII for almost 20 years.

Well-established relationships embodied in our work with BAILII, the Free Access to Law Movement (FALM) http://www.falm.info/, the Foreign Law Research (FLARE) group of libraries http://ials.sas.ac.uk/about/leadership-and-collaboration/flare-foreign-law-research , and with LLMC-Digital, the US-based non-profit cooperative of libraries http://www.llmc.com/, will help provide drive and direction for future developments. 


\section{IALS Digital resources}

At the IALS Digital launch event two panels of speakers described some of the resources that have been developed at the Institute over the years.

The first panel (David Gee, IALS Deputy Librarian; Joe Ury, BAILII Executive Director; and Professor Catharine MacMillan, King's College London) looked at examples of collaborative initiatives based on IALS Library collections and expertise.

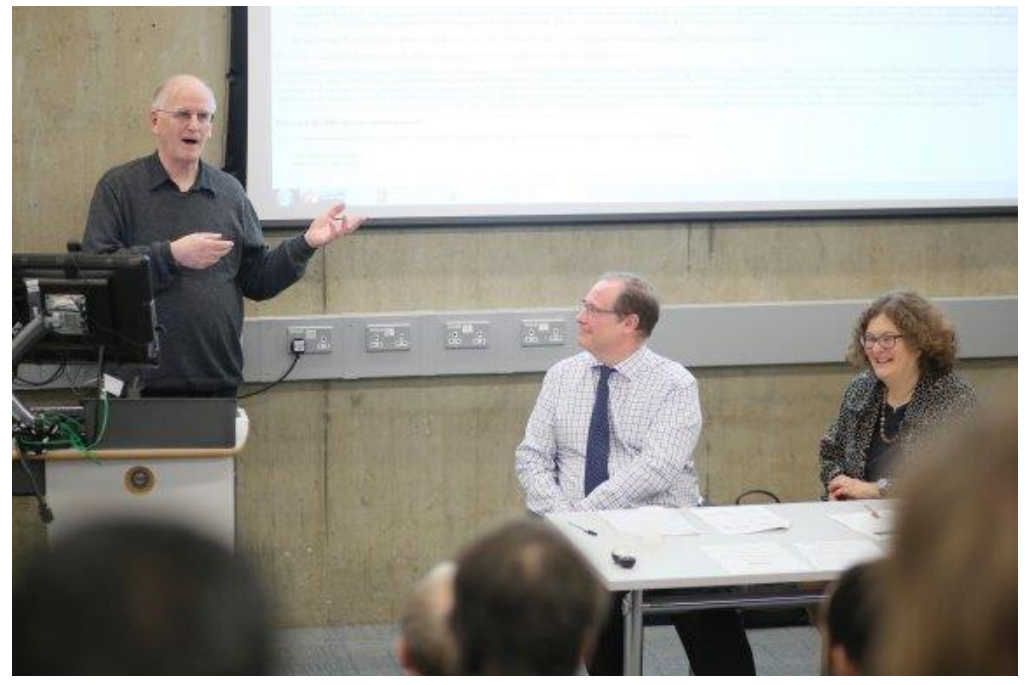

Joe Ury, David Gee, Professor Catharine MacMillan

The second panel (Professor Jane Winters, School of Advanced Study; Ronan Cormacain, IALS doctoral research student; and Professor Diamond Ashiagbor, Professor of Law and Director of Research, IALS) focused on Open Access and the Institute's commitment to that agenda, particularly in extending open access publishing for law.

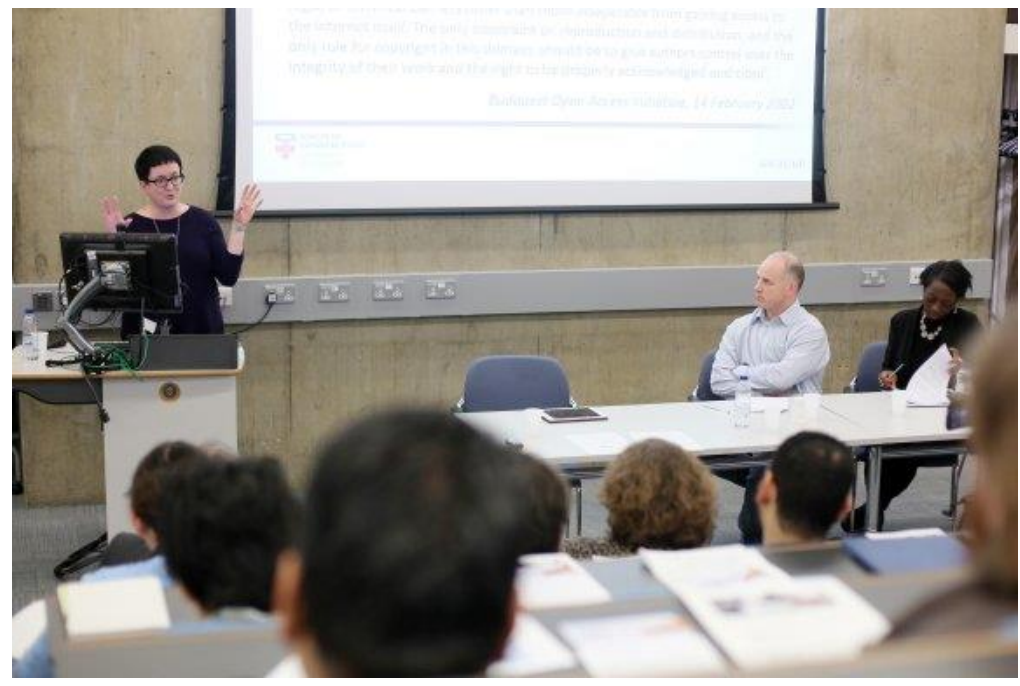

Professor Jane Winters, Ronan Cormacain, Professor Diamond Ashiagbor

The panellists very kindly shared their insights and illustrated the aims and agenda for IALS Digital going forward, describing some of the new and updated versions of research tools being launched to support digital legal scholarship. 
The IALS Digital team is working progressively to introduce new versions of the wellestablished and freely available IALS legal research tools which will be based in the Drupal content management system on the IALS website:

Eagle-i (Electronic Access to Global Legal Information) our database of quality-selected free law websites http://ials.sas.ac.uk/digital/ials-digital-resources/eagle-i-internet-portal-law and FLAG the Foreign Law Guide to the print and microform holdings of foreign, international and comparative law in the UK's academic, national and specialist law libraries will be the first available, followed by the Current Awareness for Legal Information Managers (CaLIM) database of current awareness information giving bibliographic details of newly published books and journal articles http://ials.sas.ac.uk/calim-current-awareness-legalinformation-managers; Current Legal Research Topics (CLRT) the database of working titles of MPhil and PhD research currently underway in universities in the United Kingdom http://ials.sas.ac.uk/clrt-current-legal-research-topics-database and the FLARE Index to Treaties http://ials.sas.ac.uk/digital/ials-digital-resources/flare-index-treaties. A cross-search of these resources utilising the Solr search engine is also being introduced.

\section{What do we mean by digital legal scholarship?}

IALS Digital links the Institute's digital projects to its research networks through research workshops, roadshow presentations, and training and public engagement events. Such events help to raise awareness of services, initiate research projects, exploit recently created resources and help researchers to realise the potential of newly development data and research tools, enhanced content, academic commentary, and training opportunities. In this way we see IALS Digital helping the research community in the application of digital techniques and methods for legal researching, using technology-enabled approaches that are beneficial for the research process itself and essential for research output, dissemination, publication and impact.

In practical terms our definition of digital legal scholarship includes:

- The application of technology to deliver new information and understanding - to stimulate new types of legal research.

- Use of open source software, platforms and resources.

- Promotion of Open Access and Open Law agendas.

- Enhanced data collection methods and analysis.

- Use of tools for locating information and giving access to new content.

- Options for the reuse of content - adoption, adaptation and presentation.

- Online engagement and interaction with the academic community and network of research participants.

- Use of social media and peer review to add research value and build social public relevance, and in particular as means to explore lateral thoughts - to test preliminary ideas and gather new ideas, to facilitate team ups, discover useful technical tools and share practical skills.

Additionally there are affinities between digital legal scholarship, legal education and the approaches of digital humanities $(\mathrm{DH})$ working at the intersection of computing and the disciplines of the humanities to create research materials, research tools and to stimulate new thinking. Each derive from and celebrate "imagining" as a central human quality. The traditional subject areas embraced by Law and Humanities such as Legal History, Law and Linguistics, Law and Literature, Law and Philosophy are complemented in digital legal 
scholarship by socio-legal topics and matters of public interest that help explore and evaluate the wider and deeper social and human relevance. They draw on and illuminate both the practical and thoughtful aspects of the discipline of law - valuing human consciousness and sharing social conscience. In a sense these aspects of law are celebrated by "The Mind of Justice" and "The Light of Reason" which Andrew Motion evokes in The Supreme Court poem written to mark the creation of the UK Supreme Court and enscribed on the semi-circular stone benches opposite the main entrance to the UKSC in Parliament Square. https://www.supremecourt.uk/visiting/new-artwork.html\#poem (Andrew Motion, Poet Laureate 1999 - 2009)

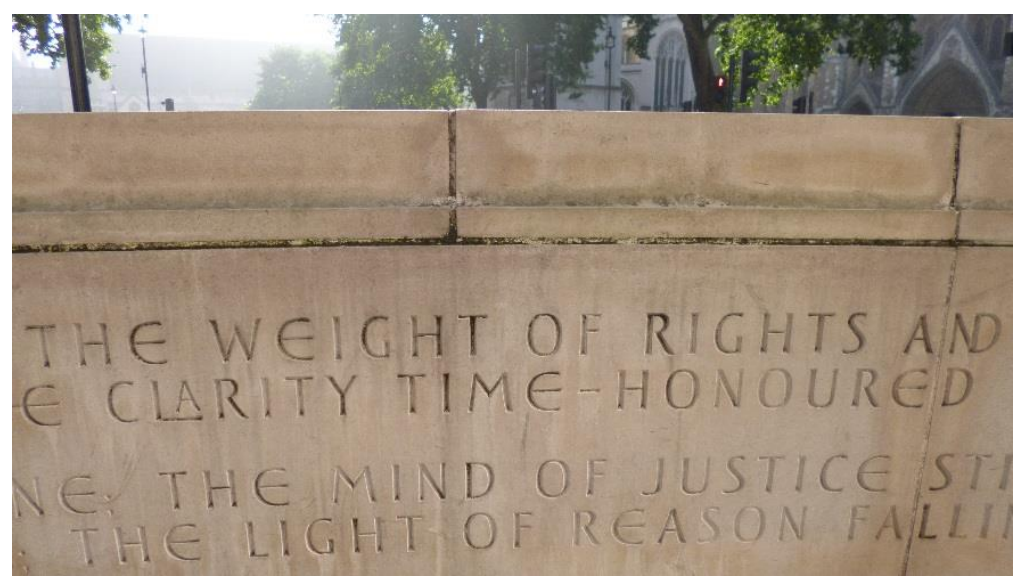

In these ways we see digital legal scholarship involving methodological and interdisciplinary approaches (writing, communicating, processing and documenting skills) that cross boundaries between disciplines, which are concerned with human experience, ethics, emotions and empathy, which potentially can inform legal design and policy and place law in context, in social settings (with "society" as "client") and as part of a cultural conversation and wider heritage concerned with protecting humanity and safeguarding individual and collective rights.

\section{Transforming information}

Appropriately in the Institute's $70^{\text {th }}$ anniversary year one of the earliest legal information projects at IALS illustrates the benefits gained from digital forms. The Collation of Legal Research, listing the details of legal research topics being pursued by research students based at institutions across the UK, began life as a few manually typed foolscap pages. It later became the Current List of Legal Research Topics, released periodically as a paper listing. A compilation of completed research details followed with IALS eventually publishing a comprehensive volume in 1985 entitled Legal research in the United Kingdom 1905-1984 containing a list of completed legal research topics from the earlier years of the 20th Century to 31 July 1984 .

In the 1990s the information was transferred and updated in the CLRT Current Legal Research Topics database http://ials.sas.ac.uk/clrt-current-legal-research-topics-database and UKLR Legal Research in the United Kingdom in the 20th Century database http://ials.sas.ac.uk/digital/ials-digital-resources/legal-research-united-kingdom-20thcentury. The digital versions help chart the development of legal research interests in the UK in the 20th Century, detail early work by many influential legal scholars, and reveal topics of recurring currency - providing themes and ideas for further research and fresh approaches. 
Links to available print and online theses in EtHOS and other sites have been added to the digital version.

Putting the information into a database and in digital form means it becomes something intrinsically more than just the original facts. It triggers new connections and thoughts, reveals new facts, and trends. It produces what might be called the "Digital benefit" where newly adjacent information produces creative sparks, generates new ideas and new insights, resulting in new knowledge. The evidence of growth of legal research over time and in terms of student numbers, range of topics and in spread of University locations across the UK, the growth in the variety of jurisdictional research being pursued (with wider world coverage through the decades) becomes, via the digital version, open to new research techniques and data visualization presentations.

\section{Open Law initiatives}

Through the work of IALS Digital the Institute continues to fulfil a commitment to free access to law and public benefit principles, expressed through its membership of the Free Access to Law Movement; in the hosting of BAILII since its foundation in the UK; in acting as the London contact point for the Commonwealth Legal Information Institute (CommonLII) http://www.commonlii.org/; in its successful open journals project and its new open monographs project.

The worldwide Free Access to Law Movement (FALM) is an alliance of over 50 member institutes and organisations around the world which subscribe to the Declaration on Free Access to Law and collaborate in the free provision of legal information and on global policy issues. The Declaration appears at http://www.worldlii.org/worldlii/declaration/ which also lists the member organisations based in countries and regions such as Australia, Canada, Cyprus, Hong Kong, India, Italy, the Pacific Islands, Philippines, Southern Africa, Uganda, and the USA. Knowledge, know-how and best practice sharing within the movement helps parallel developments in interface, search, retrieval and interoperability solutions strengthening the means to effective comparative research found in services like WorldLII and LawCite http://www.bailii.org/form/search lawcite.html.

\section{Digitisation projects - case papers of the Judicial Committee of the Privy Council appeals}

A successful digitisation initiative at IALS in 2015 funded by the School of Advanced Study's Strategic Development Fund provides researchers with online open access to many of the additional case papers the Institute Library holds relating to historic Judicial Committee of the Privy Council decisions. Over 5,000 searchable PDFs were created of case papers from the IALS collection from 1929 -1985 (effectively a full paper set from 1950 to 1985) involving more than 35 countries and some selected papers from earlier judgments of special interest to legal scholars. The digitised case papers are available alongside the judgment texts on the BAILII service http://www.bailii.org/uk/cases/UKPC/. 


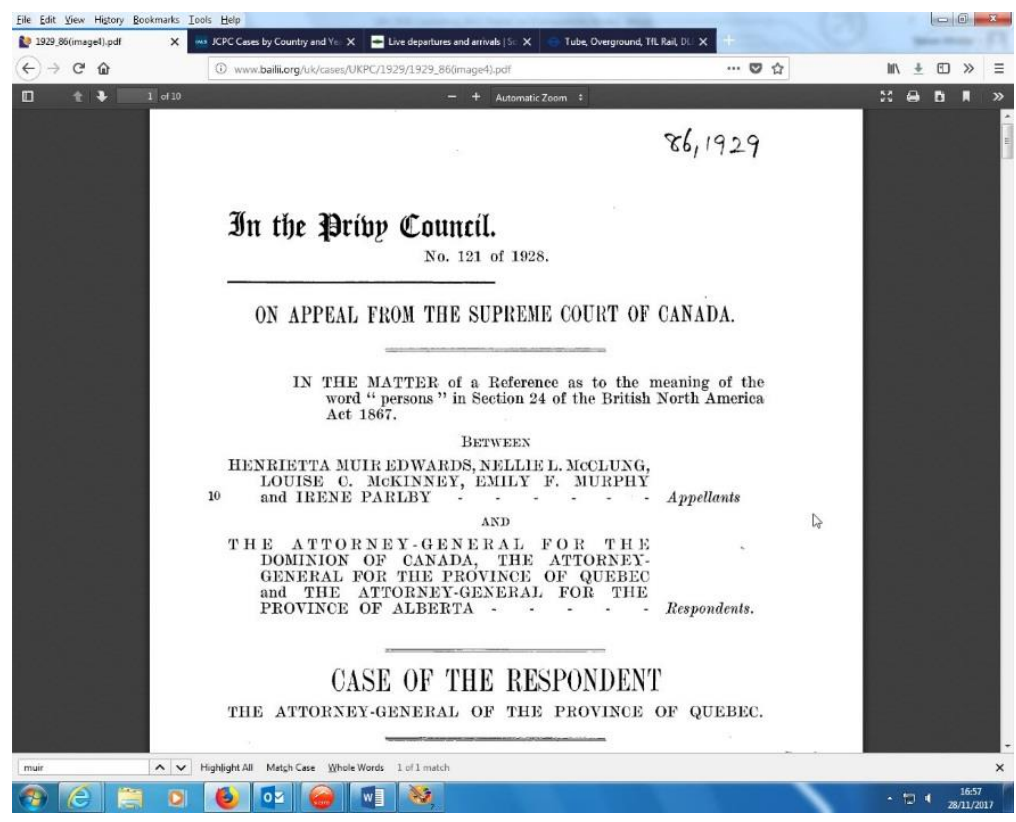

At the IALS Digital launch Professor Catharine MacMillan (Professor of Law, Dickson Poon School of Law, King's College London) gave a very entertaining and informative presentation highlighting her encounters with the JCPC case papers held in the IALS basement and describing the ways in which IALS digitisation initiatives, making the papers freely available on BAILII, had helped her research. Catharine shared an interest in the origins of some of the papers where margin notes, preserved in the digitisation, suggested annotation by the judge rather than counsel or clerks.

The case papers give an insight into the work of the legal professionals at the time, express the arguments they employed and reveal the law and the legal process in action, impacting on individual lives. The full range of stories they tell illustrate Colonial devolution and development of Common Law and international law, encompassing public, personal, social, political, cultural and human issues.

Catharine's talk referenced key cases such as the "Person case" or "Famous Five" case - a Canadian appeal Henrietta Muir Edwards and others (Appeal No. 121 of 1928) v The Attorney General of Canada (Canada) [1929] UKPC 86 from 18th October 1929. In 1927 five Albertan women campaigning for legal and political equality had petitioned the federal government of Canada on whether women could sit as members of the Senate. The answer hinged on whether s24 of the British North America [Canada] Act 1867 which formed the basis of Canada's Constitution intended the phrase "qualified persons" to include women; if it did then women were entitled to stand for Senate. When the Supreme Court of Canada ruled that it did not, Alberta's "Famous Five" appealed to the JCPC in London which overturned Canada's Supreme Court decision, advancing a new approach to constitutional interpretation that became known as the "living tree doctrine" which is still in use across the Common Law world today.

The JCPC case papers provide information to help researchers discover and evaluate horizontal influences and legal variation in a worldwide context. Some contain maps and photographs or diagrams from the crime scene. In adding value and understanding to the judgments themselves, the papers also provide appropriate source material for future 
experiments to take better advantage of digital capabilities such as interaction with integrated images and embedded videos in legal scholarship.

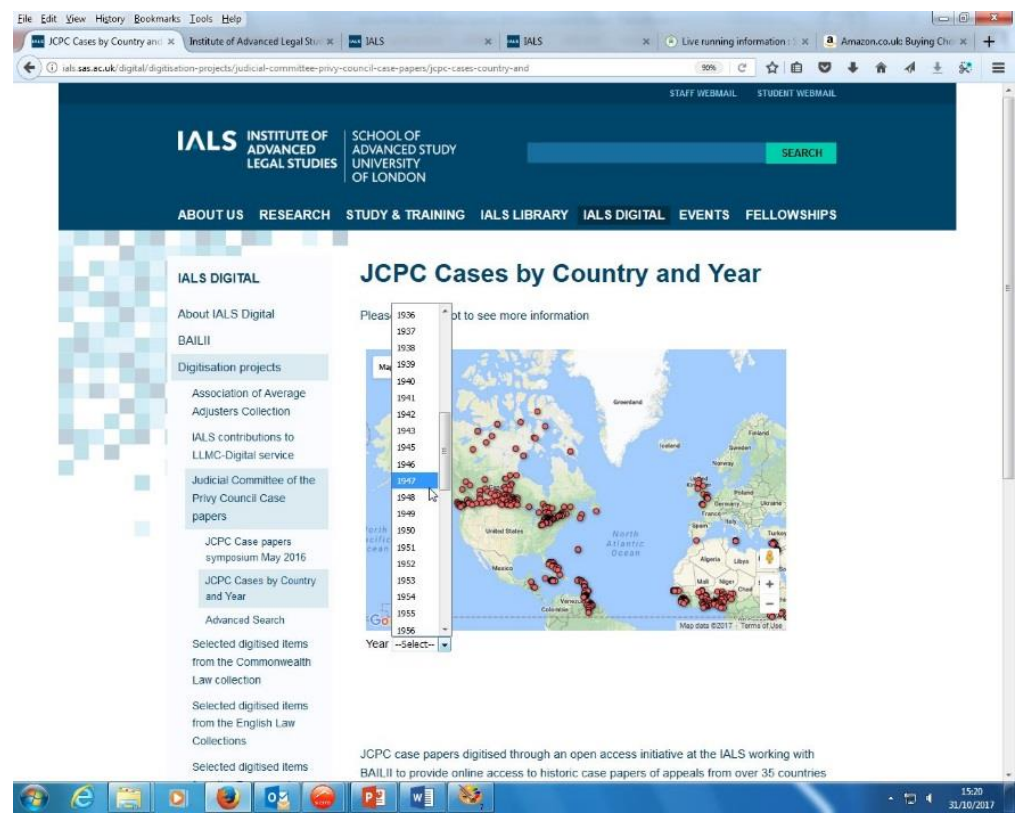

At the IALS Digital launch Joe Ury (Executive Director, BAILII) demonstrated where to find the JCPC decisions and associated case papers on BAILII. Joe reminded us that BAILII is the premier free legal information website in the UK, heavily used by universities, the public and practitioners with over 2,000 visitors per day. Digital content from IALS is freely available by agreement on BAILII. A visual interface based on an information visualization interacting with the data to show the jurisdictional distribution and country coverage is offered on the IALS website with options to follow hotspots or filter by year of judgment and then pass through to the relevant documents on BAILII. The interactive geographic visualization based on google maps provides alternative views and routes to the information, supporting new discoveries and reinforcing understanding. We see this project very much as an example of the digitisation work IALS Digital will undertake and a model for closer working planned with BAILII.

\section{BAILII Leading Case Law by Subject}

Joe's presentation also highlighted the Leading Case Law by Subject section on BAILII which resulted from the earlier Joint Information Systems Committee (JISC) funded Open Law project at IALS. This core collection of landmark cases (significant older judgments from England and Wales, Scotland, and Northern Ireland) identified by the legal academic community, can be readily referenced in theses, dissertations, papers, bibliographies, reading lists and VLEs with persistent open, non-proprietary, password and pay-wall-free URLs to help meet the needs of those teaching and studying law at all levels. The service offers a freely and openly available database of important legal judgments and reports to support teaching and learning in legal education in further and higher education across the UK. Using the Leading Case Law by Subject collection of materials on BAILII, lecturers can provide teaching materials which link directly from their own websites to a judgment or a paragraph in a judgment on BAILII and librarians can catalogue cases as part of their electronic resources collections. 


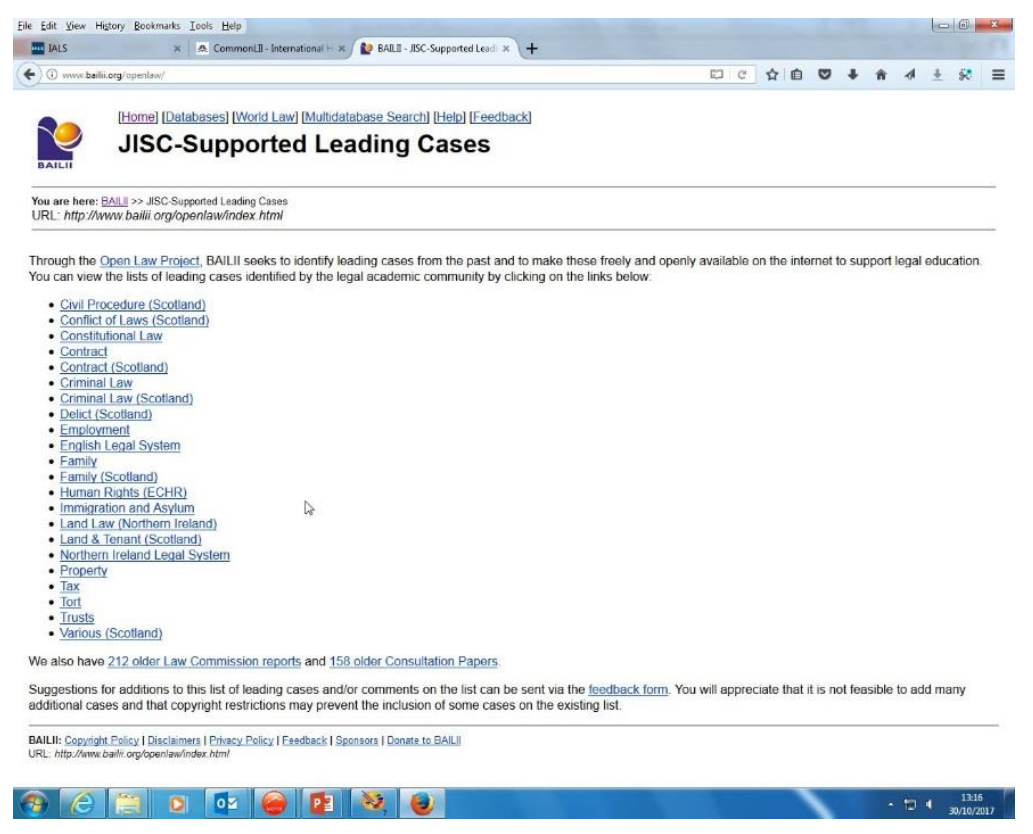

\section{Foundations of the Common Law Library}

In a video greeting at the IALS Digital launch Professor Graham Greenleaf AM made an exciting announcement about a new AustLII led initiative to build an online library called Foundations of the Common Law 1215-1914 as a free resource based on the CommonLII service.

AustLII will receive a 500,000 Australian dollar grant from the Australian Research Council complemented by matching funds from 11 Australian universities to take forward the project to digitise the key pre-1915 case law and other raw materials for research from across the whole Common Law world, working in co-operation with 12 legal information institutes including IALS Digital and BAILII.

The continuing contemporary importance of Common Law, interdependence of legal developments and the longevity of case law influences is illustrated in an example from Graham Greenleaf. Heydon's case (1584) originated the "mischief rule" in statutory interpretation and developed the court's role in clarifying the purpose and advancing the remedy of the act. The results of a LawCite search on CommonLII for Heydon's case from the English Reports (Heydon's Case [1584] EngR 9; (1584) 3 Co Rep 7; 76 ER 637 show how many recent cases across several common law jurisdictions are referring to this historic case (at time of writing 6 in 2017, 6 in 2016, 8 in 2015, 7 in 2014 - from Australia, Fiji, India, Ireland, Tonga, Vanuatu, and the UK). 


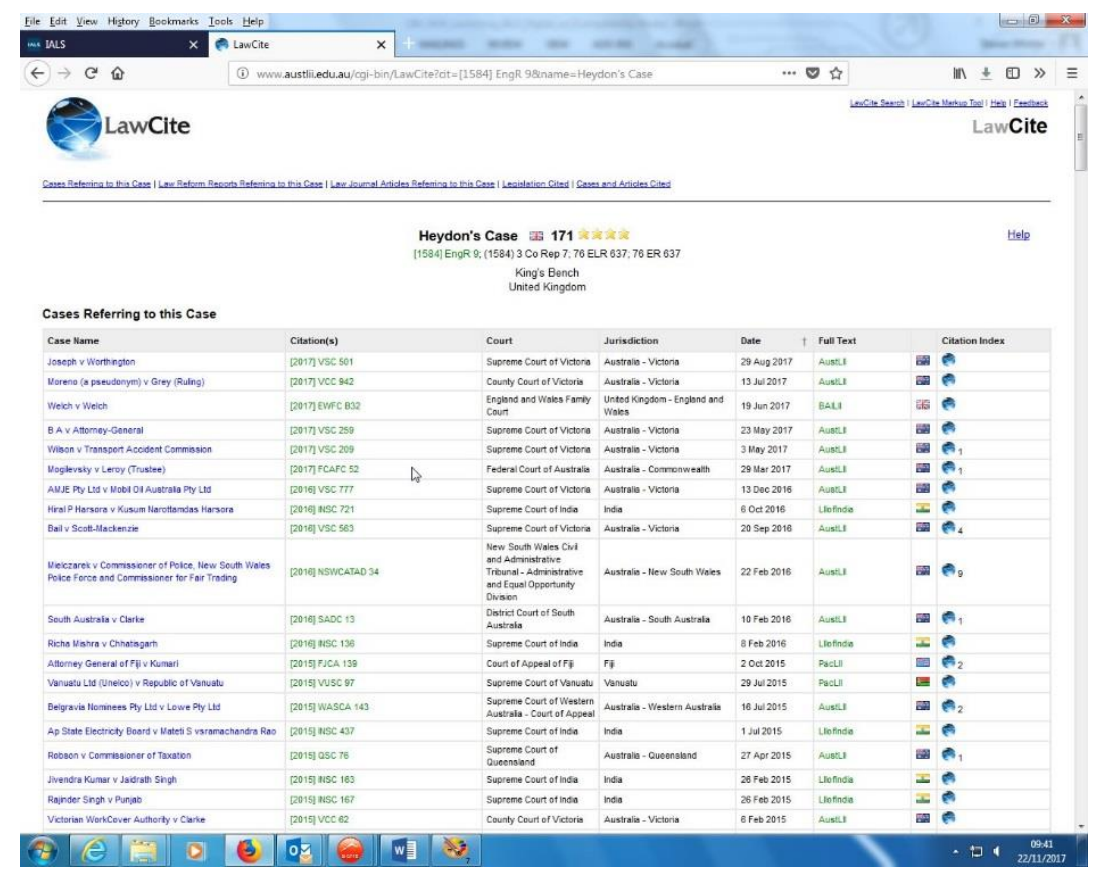

In 2016 AustLII established an International History of the Common Law prototype on CommonLII to demonstrate the potential benefits of the legal research and digital memory initiative and help secure development funding. As proof of concept IALS contributed 107GB of data digitised from over 5,300 pages of pre-1900 law reports from IALS Library's collections for Barbados, Ceylon, Jamaica, Trinidad \& Tobago and the Windward Islands.

- Barbados Law Reports volume 1 + volume 2

- Appeal Reports (Supreme Court of Ceylon edited by C.A. Lorenz) 1858-59

- Balasingham reports volume $1+$ volume 2

- Ceylon Law Reports volumes 1-3 1890-97

- Ceylon Supreme Court Reports volume 1 1892-93 + volume 21893 + volume 3 1893-95

- Supreme Court Decisions of Jamaica (1774-1923)

- Reports of Judgements Delivered in the Supreme Court of Trinidad \& Tobago volume 1 1893-1910.

- Windward Islands Appeal Cases (1866-1904)

IALS Digital is delighted to have the opportunity to build on this work with AustLII in the near future. The Foundations of the Common Law Library will provide an important new resource for open scholarship and enquiry, reflecting the inter-relationships relevant in today's law and recognition of Common Law as part of humanity's intangible cultural heritage - originating over 800 years ago, and growing beyond restrictive colonial introduction to become a joint international enterprise over the course of $200+$ years to form one significant pillar of the rule of law and human rights.

\section{The importance of the Open Access agenda}

At the IALS Digital launch event Professor Jane Winters (Professor of Digital Humanities, School of Advanced Study) set the context for the Institute's work on open access projects by examining the Budapest Open Access Initiative definition of OA from the 14 February 2002, explaining the aims and ideas of the Open Access movement, looking at the benefits 
of Open Access for authors and the benefits for readers and identifying emerging challenges for open scholarship - in sourcing and publishing commentary for free access:

"By "open access" to ... literature, we mean its free availability on the public internet, permitting any users to read, download, copy, distribute, print, search, or link to the full texts of these articles, crawl them for indexing, pass them as data to software, or use them for any other lawful purpose, without financial, legal, or technical barriers other than those inseparable from gaining access to the internet itself. The only constraint on reproduction and distribution, and the only role for copyright in this domain, should be to give authors control over the integrity of their work and the right to be properly acknowledged and cited'. Budapest Open Access Initiative, 14 February 2002 http://www.budapestopenaccessinitiative.org/

For academic authors OA provides clear benefits in making original work accessible globally, irrespective of ability to pay, vastly increasing the potential (and actual) readership for the research and opening up that research to new kinds of audience - interested public, policymakers, and journalists. Trends from usage figures show increases in downloads, and most likely increases in citations with additional benefit drawn from imaginative engagement with the work enabled through digital format and open online presence.

For readers OA delivers the possibility of wider and deeper access to commentary at a time when even the best-funded and well-resourced universities can't subscribe to everything. By removing barriers to access, technical or financial, OA makes it possible for knowledge to enter the public domain more quickly - and access to previously gated knowledge must be of growing importance in an era of 'fake news'.

In the traditional commercial publishing sector there have been warnings of "an existential crisis for academic books" (https://www.timeshighereducation.com/news/worst-sellerswarning-existential-crisis-academic-books) with sales of academic titles declining by $13 \%$ between 2005 and 2014. At the same time the number of individual titles sold rose by $45 \%$ so average sales per title fell from 100 to 60 copies. In 2014 the Research Excellence Framework (REF), the UK's system for assessing the excellence of research in higher education institutions, revealed that only around $50 \%$ of books submitted to the REF sold at least one copy in the period 2008-2014.

There are several questions and challenges raised by the pace and nature of changes in the publishing landscape. With the Open Access culture evolving very quickly, the long-term sustainability of many new open access platforms is being questioned. Academic authors and readers are asking what are the new markers of trust and authority in an OA landscape? Scholarly practices and expectations are dealing with concerns about licensing and re-use and with problems of discoverability (a worry that work might be openly available but remain effectively invisible on an unknown site) and a lack of recognition for disciplinary differences, in ways of publishing and in ways of reading.

In a natural development of its established national role in legal information delivery the IALS experience in open journals and most recently in open monograph initiatives, its work on non-exclusive licensing of shared OA content, and in metadata creation, visibility and accessibility via new generation library systems and publishing platforms - give the Institute an important opportunity, through IALS Digital, to help offer continuity and development in the OA publishing environment. 


\section{IALS Open Access journals}

A six-month project in 2011 in the School of Advanced Study, funded through the campusbased publishing strand of a JISC Digital Infrastructure programme, developed the School's Open Journals System - a re-usable journal production and online publication system linked to the SAS open access institutional research repository - helping the School and its member institutes like IALS source and deliver academic commentary for free.

SAS Open Journals is an installation of the open source Open Journal System produced by the Public Knowledge Project, a non-profit collaborative initiative involving Stanford University, Simon Fraser University, University of British Columbia, University of California, and the University of Pittsburgh https://pkp.sfu.cal. The system includes a full range of features supporting a whole life-cycle manuscript workflow through to delivery of the finished publication via a customisable web interface. The resulting integrated service provides the School with a digital journal publication facility, capable of creating new online journals and delivering established titles in a new way - offering a system that is able to provide varying journal workflows from whole production process to final PDF presentation only.

IALS has used the service to create a portfolio of open access journals - two are transitions from previously print published journals and one is born-digital. Collectively these three titles have almost 1.5 million lifetime views and downloads since they went live in SAS OJS in 2011, 2013 and 2014 respectively:

Amicus Curiae - is the official journal of both the Society for Advanced Legal Studies and the Institute of Advanced Legal Studies. The open version includes over 700 articles by more than 450 authors with many articles by legal experts, judges, practising lawyers, and scholars (http://journals.sas.ac.uk/amicus/).

Digital Evidence and Electronic Signature Law Review - is an open access version of the innovative journal on specialist legal topics related to electronic evidence and electronic signatures. The open version makes the original print volumes 1-10 freely available and presents volume 112014 onwards as born digital publications. This journal brings articles, legal developments and case reports to academics, practitioners and the industry in relation to digital evidence and electronic signatures from across the world.

(http://journals.sas.ac.uk/dees/r/). Articles in the 2017 volume cover topics such as: digital alibi evidence; tracking of mobile ping data; forced biometric authentication; establishing possession, custody and control through airport electronic baggage tags; enforceability of electronic arbitration agreements; electronic evidence exchange across the European Union; and another method of stealing cash from ATMs.

IALS Student Law Review - is an open access, peer-reviewed law journal run by IALS doctoral legal research students assisted by an academic member of staff at the Institute. The journal is intended as a showcase for new writing by legal scholars from postgraduate students and early career scholars to well-established academics.

(http://journals.sas.ac.uk/lawreview/).

At the IALS Digital launch Ronan Cormacain (IALS doctoral research student and former Editor-in-chief of the IALS Student Law Review) gave an insight into the practicalities involved in producing and promoting the journal.

The inaugural issue of the IALS Student Law Review was made freely available online in SAS Open Journals in September 2013 as a born-digital journal. Two issues are usually produced per academic year featuring peer reviewed papers by new and established writers 
- legal research students, scholars, lawyers investigating legal issues from single or multiple vantage points whether topically or jurisdictionally. The journal provides a forum which supports critical thinking, questioning and learning where authors have freedom to test evidence and investigate knowledge. For example a themed issue in 2014 featured articles examining questions of law reform and the need for mandatory reporting of child abuse http://journals.sas.ac.uk/lawreview/issue/view/318/showToc.

Ronan described the benefits to students who work on the journal, juggling their own research commitments with the voluntary practical experience of running a journal. Students on the editorial team have enhanced their networking skills (from entering discussions with reviewers, academics, and authors), building their organisational skills (from the publishing production process of receiving articles, scheduling reviews, and managing proofs and revisions) and demonstrating diplomatic skills (when soliciting comment, dealing with constructive criticisms and in their handling of the peer review process with much tact and understanding). Their work has given the students a familiarity with the academic publishing process, potentially assisting career development and leading to opportunities for further academic work. It has also allowed them to build and share awareness of an open access publishing model and its role in removing barriers and extending the reach of academic writing to find a wider audience where work can be read and cited by many. The inclusion of the ISLRev in the Directory of Open Access Journals (DOAJ) https://doaj.org/ has been a very welcome acknowledgment of the journal's commitment to full open access and a tribute to the effort of all those involved in its production.

The School of Advanced Study's subscription with CrossRef means that unique Digital Object Indicators (DOIs) are assigned to the articles published in titles through the SAS OJS platform. A DOI is the ISO standard associated with the article itself, as the intellectual object, rather than the hosting system, so the link resolves to revised URLs whenever a host site changes. In the ISLRev, the use of DOIs as persistent identifiers for content and, when available, ORCID iDs as the persistent digital identifier distinguishing individual authors help make the scholarship more readily visible, accessible, flexible and usable. Additionally, "cited-by" linking and "altmetrics" are used to count mentions in social media such as blogs, Facebook and Twitter and so help track an article's influence and measure its impact beyond the most immediate and likely audience. Future work will extend beyond PDF as the main format and means of distribution for law journal articles. We plan, with colleagues in the School, to develop the open journals platform to offer articles in HTML/XML format well as PDF.

Building on this successful experience with open access journal publishing the Institute has been keen to also develop an open access monograph publishing capability in support of UK open legal scholarship.

\section{OBserving Law - the IALS Open Book Service for Law}

At the IALS Digital launch event Professor Diamond Ashiagbor (Professor of Law and Director of Research, IALS) described the latest work at the Institute to establish the IALS Open Book Service for Law as part of an open access monograph press initiative of the School of Advanced Study called the Humanities Digital Library (http://humanities-digitallibrary.org). The Humanities Digital Library, again utilising open source software created by the Public Knowledge Project, launched in January 2017 and continues to grow month by month in content and usage. It combines new open access publications with digital versions of existing print titles that are now freely available to, and reusable by, anyone. Each title is 
published as an open access PDF, with copies also available to purchase in print and epub formats for e-reader devices. The IALS service on the SAS platform, OBserving Law (http://ials.sas.ac.uk/digital/humanities-digital-library/observing-law-ials-open-book-servicelaw), aims to provide a showcase for the vibrant state of legal scholarship, publishing the best monographic works in law, demonstrating the stature of 'traditional' academic publishing and reinvigorating its role.

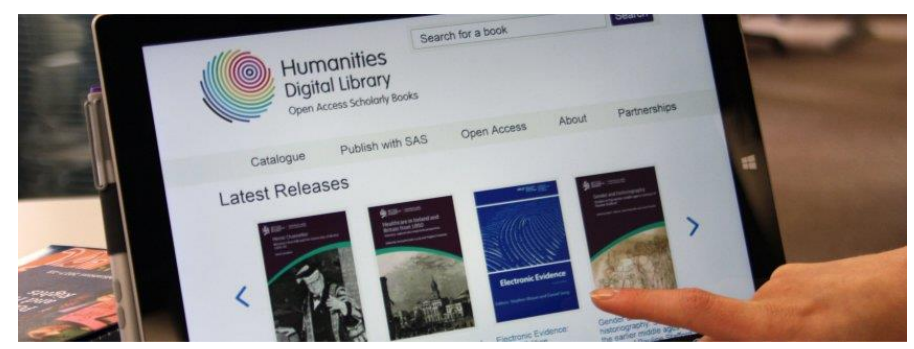

Diamond described the changing environment and prospects for academic publishing with a number of open monograph press services becoming available (such as those at University College London http://www.ucl.ac.uk/ucl-press, Goldsmiths, University of London https://www.gold.ac.uk/goldsmiths-press/ and University of Westminster https://www.uwestminsterpress.co.uk/) and suggesting that open access could well provide a way of launching a new generation of university presses. As a natural extension of the Institute's role in research promotion and facilitation the IALS Open Book Service for Law aims to provide a service open to writers from across the UK legal research community and specialising in Law.

Titles from OBserving Law, the IALS Open Book service for Law, in 2016-2017 include the fourth edition of Electronic Signatures in Law written by Stephen Mason (published November 2016) and an up-to-date edition of Electronic Evidence edited by Stephen Mason and Daniel Seng with a team of specialist contributors and experts in the field (published May 2017). Stephen is an IALS Associate Research Fellow, a barrister and leading authority on electronic signatures and electronic evidence. His enthusiasm and active support for Open Access have been invaluable to the initial project. Appropriately, as the premier title in a new service bringing together the results of legal and historical research, the opening chapter of Electronic Signatures in Law $4^{\text {th }}$ edition is a fascinating piece of writing on legal history for a legal and non-legal readership, representing significant scholarship in outlining the development of the legal signature and tracing the emergence of current digital forms and consequences from their use. Paragraph numbering adopted in the first two law titles also provides the School's wider project with examples of options to address format specific pagination issues and facilitate consistent citation. Statistics show that the two law titles are both in the top three download figures from the Humanities Digital Library, achieving more than 3000 free downloads and additional purchase sales of print-on-demand (POD) or epub/Kindle versions.

The Editorial Board of the IALS Open Book Service for Law comprises distinguished legal scholars and law librarians, with Richard Hart (of Hart Publishing) as consulting editor. The current membership is: Professor Diamond Ashiagbor (IALS), Professor Fiona Cownie (Keele University), David Gee (IALS), Richard Hart (Consultant Publisher), Professor Rosemary Hunter (Queen Mary University of London), Professor Ambreena Manji (Cardiff University), and Steven Whittle (IALS). The IALS Editorial Board is supported by an Advisory Board of legal scholars undertaking peer review and acting as consultant editors with specialist subject expertise in law. The Advisory Board chaired by Jules Winterton (IALS 
Director) includes leading individual legal scholars from across the UK and internationally and representatives for scholarly and professional associations in law such as the Association of Law Teachers, the British and Irish Association of Law Librarians, the Legal Research Network, the Society of Legal Scholars, and the Socio-Legal Studies Association. Such scholar-led editorial oversight will help us develop a service that can support established writers, new voices and future talent with opportunities to experiment and grow creatively.

\section{The IALS PhD Thesis Book Prize}

To help encourage such new writing Professor Diamond Ashiagbor announced at the IALS Digital launch event an annual book prize, the winner of which is awarded a publishing contract for their doctoral thesis to be published as an open access monograph by the IALS Open Book Service for Law. The competition for the IALS PhD Thesis Prize is an exciting opportunity for authors in London, across the UK and worldwide whose doctoral thesis has been submitted or passed in recent years. The winning thesis will appear as an OA monograph in the IALS Open Book Service for Law under a creative commons licence (free to download but with POD options available to purchase for a price). The competition is open to authors whose thesis for a PhD in Law has been submitted or passed in the previous two years - for the initial award that is after 1 November 2015 and before 1 November 2017. Eligible authors are invited to register online and complete the proposal form http://ials.sas.ac.uk/digital/humanities-digital-library/observing-law-ials-open-bookservice-law/ials-phd-thesis-book.

\section{Objectives for IALS Digital}

Our strategy for digital developments at the Institute will be realised by the new overall identity of IALS Digital and characterised by new connections and collaboration. Looking forward we aim to:

- Extend scholarly communications, content creation and curation (with explicit editorial roles in digital publication, via the website, web databases, open access journals and open access book platforms, social media, academic events and outreach participation).

- Further develop open law research materials, asset management and preservation (through digitisation initiatives).

- Further develop roles in investigating and applying best practice re: metadata and resource description, search and retrieval methodology and technology, InfoVis visualization aids, and interactive user interfaces and experiences.

- Further develop training roles with support for technology-enabled research (through group sessions and one-to-one appointments in the Library) and web delivery (via Libguides http://ials.sas.ac.uk/library/ials-collections/ials-library-guides and Law PORT http://ials.sas.ac.uk/digital/ials-digital-resources/law-port).

- Explore the opportunities for consultancies and funded projects in collaboration with UK and overseas partners - building on the IALS national and international reputation as a partner of choice for digital information initiatives in law and extending the benefits of IALS as a neutral HE partner engaged with legal education, legal research, practitioners, the judiciary, and policy-maker communities.

There is much to do. The launch of IALS Digital begins a new chapter for the Institute and its Library that will help ensure in the years ahead that the IALS is well placed to continue 
advances in free access to law - expanding OA delivery and promotion; furthering the possibilities of computing for legal research; and supporting the current and future ambitions of digital legal scholarship.

\section{Keeping in touch with IALS Digital}

- Email IALS ials@sas.ac.uk

- Visit IALS website ials.sas.ac.uk

- Follow the IALS Blog http://ials.blogs.sas.ac.uk/

- Like us on Facebook https://www.facebook.com/advancedlegalstudies/

- Follow us on Twitter https://twitter.com/IALS law

- IALS videos http://ials.sas.ac.uk/digital/videos presentations from public lectures and events such as the IALS $70^{\text {th }}$ Anniversary celebrations and the launch of IALS Digital itself.

This article has been developed from presentations delivered at the IALS Digital launch at the Institute of Advanced Legal Studies on Thursday $16^{\text {th }}$ November 2017. Many thanks to all the other speakers:

- Professor Diamond Ashiagbor (Professor of Law and Director of Research, IALS)

- Ronan Cormacain (IALS doctoral research student at IALS)

- David Gee (IALS Deputy Librarian)

- Professor Graham Greenleaf (Professor of Law \& Information Systems at UNSW Australia Faculty of Law, and as Founding Co-Director and Senior Researcher of the Australasian Legal Information Institute AustLII)

- Professor Catharine MacMillan (Professor of Law, Dickson Poon School of Law, King's College London)

- Joe Ury (Executive Director, BAILII)

- Professor Jane Winters (Professor of Digital Humanities, School of Advanced Study)

Photography: Lloyd Sturdy http://www.lloydsturdy.com and Steven Whittle

\section{Biography}

Steven Whittle BA, MA is the IALS Digital Manager at the Institute of Advanced Legal Studies, School of Advanced Study, University of London. He is a member of the Institute Management Committee and the Institute Library Management Team.

He is the manager of the IALS Information Systems Team; manages IALS Digital Resources; is editor for the IALS website (www.ials.sas.ac.uk), social media presence; and has helped to develop a number of national online services for law on the IALS site including the Eagle-i Internet Portal for Law, FLAG - the Foreign Law Guide, and Flare Index to Treaties. In 2010 he was honoured to receive the Wallace Breem Award from the British and Irish Association of Law Librarians (BIALL) in recognition for work on these services.

He has also managed digitisation project work at IALS and led IALS involvement in the School of Advanced Study's Open Access initiatives and collaborations, including development of the IALS collections on the SAS-Space e-prints e-repository, participation in a JISC funded initiative to create the SAS Open Journals System capability and subsequently has developed a number of open access journals for IALS on the SAS OJS. His latest work has focused on the development of the IALS Open Book Service for Law on the SAS Humanities Digital Library open monograph publishing platform. 